\title{
CHOROIDAL THICKNESS IN PATIENTS WITH DIABETIC MACULAR EDEMA
}

\author{
Amash Aqil, Muhammad Moin, Khadijah Abid*, Ahsan Mehmood \\ Lahore General Hospital, Lahore Pakistan, *College of Physician and Surgeons Pakistan, Karachi Pakistan
}

\begin{abstract}
Objective: To evaluate central macular thickness and choroidal thickness in patients with macular edema due to diabetic retinopathy versus controls.

Study Design: Cross-sectional comparative study.

Place and Duration of Study: Department of Ophthalmology, Lahore General Hospital, Lahore, from Jan to Jul 2018.

Methodology: A retrospective data of 100 eyes from 50 patients having with diabetic macular edema associated with diabetic retinopathy was extracted from hospital registry. Additionally, 100 eyes of 50 individuals without any preexisting ocular conditions, comprising a control group was included in the study. Choroidal thickness measurements were made from the posterior edge of the retinal pigment epithelium to the choroid/sclera junction at subfoveal level using optical coherence tomography. Central macular thickness was also measured for all the enrolled patients.

Results: One hundred patients fulfilling the inclusion criteria were enrolled in our study. The mean age was $56.27 \pm 14.41$ years. The mean Central macular thickness of all the patients were reported as $270.49 \pm 72.38 \mu \mathrm{m}$, while the choroidal thickness was $284.89 \pm 96.51 \mu \mathrm{m}$. There was statistically significant difference in central macular thickness between both healthy and diabetic retinopathy with diabetic macular edema groups $(p=0.001)$, whereas insignificant difference existed between the two groups forchoroidal thickness $(p=0.735)$.

Conclusion: In patients with diabetic macular edema no significant change in choroidal thickness was observed compared with healthy controls, while the thickness of the retina was high in patients with macular edema due to diabetes.
\end{abstract}

Keywords: Choroidal thickness, Diabetic retinopathy, Diabetic macular edema, Optical coherence tomography.

This is an Open Access article distributed under the terms of the Creative Commons Attribution License (http://creativecommons.org/licenses/by/4.0), which permits unrestricted use, distribution, and reproduction in any medium, provided the original work is properly cited.

\section{INTRODUCTION}

The choroid is an integral part of the eye that is vital for normal retinal function. Previously, using Indocyanine green angiography and Fluorescein angiography were required to view the choroid. However, these modalities are invasive and limited in showing details of the anatomy of the choroidal layers and retinal pigment epithelium ${ }^{1,2}$. Optical coherence tomography angiography (OCTA) is a relatively recent and non-invasive investigation, which captures high-resolution images of the retinal layers. It takes three dimensional scans which can stitched together to present an enface image, these images can then be scrolled through to visualize segments the choriocapillaris, inner retina, outer retina and other area of interest ${ }^{3-5}$.

Diabetes causes a cascade of pathological changes in the anatomy of the choroid ${ }^{6}$. Some of which include increased blood vessel tortuosity and dilatation, micro aneurysms combined with aregions of ischemia. Several other studies have analyzed structures of the choroid with associated changes in diabetic patients using fourier and spectral domain optical coherence tomography $(\mathrm{OCT})^{7}$. Choroidal imaging was inadequate to

Correspondence: Miss Khadijah Abid, 7th Central Street, DHA Phase II, Karachi Pakistan

Received: 13 Sep 2019; revised received: 11 May 2020; accepted: 19 May 2020 view the histopathological effects of the disease in the past as the retinal pigment epithelium did not allow sufficient quantity of the beam to pass through. Now advancements in the incident beam being and the software upgrades in the machine allow the choroidal histopathology to be seen more clearly ${ }^{8,9}$.

Diabetic retinopathy is the leading cause of visual deterioration across the world ${ }^{10}$. The primary causes of visual loss in these patients is diabetic macular edema and proliferative diabetic retinopathy ${ }^{10}$. So, the objective of our current study was to evaluate central macular thickness (CMT) and choroidal thickness (CT) using OCT in patients with macular edema due to diabetes versus normal controls.

\section{METHODOLOGY}

It was a comparative cross-sectional study carried out at the ophthalmology department of Lahore General Hospital. A retrospective data from January to July 2018 of 100 eyes of 50 patients of age 12-98 years of either gender having diabetic retinopathy with diabetic macular edema was extracted from hospital registry. Additionally, 100 eyes of 50 individuals of same age as cases, with normal visual acuity and no existing choroidal and retinal disease were included in the study as control group for comparison. Any patients with a history of vitreo-retinal surgery, anti-vascular growth 
factor injections, or prior laser treatment for diabetic retinopathy were excluded.

Patients with diabetes were grouped in accordance to the tenets of the "early treatment diabetic retinopathy study"11. In this study, we included patients with Diabetic Macular edema(DME) that didn't have any signs of proliferative retinopathy(PDR). DME was defined as retinal thickening with area $\geq 2$ disc diameter, encompassing the macular center, and with a CMT of $>300 \mu \mathrm{m}$ which was determined by OCT.

Informed consent was collected from all patients and the research was done as per the protocols outlined in the "Declaration of Helsinki". Approval from the Ethics Review Committee of Lahore General Hospital was granted (ERB no: 0063-19).

At presentation each patient underwent a detailed systemic and ophthalmological workup. Measurement of visual acuity was done using an ETDRS chart, and a consultant ophthalmologist preformed a comprehensive slit-lamp examination. Furthermore, a Goldmann applanation tonometer was used to measure the patients intra ocular pressure, and the fundus was also examined with a superfield lens.

Patients in the diabetic macular edema (DME) group were chosen from those without any active neovascularization. Arterial blood pressure was measured along with $\mathrm{HbA1c}$ but were not included in the study. Patients with history of unregulated hypertension were excluded from the study. Furthermore, patients with age-related macular degeneration were also excluded.

The same OCT device was used to accquire OCT measurements of all the patients, (Topcon swept Source Triton, Japan) by a single person after adequate pupillary dilatation $(>5 \mathrm{~mm})$ using the chorioretinal line-mode. Low quality scans necessitated re-measure-ment. To affirm that the measurements were reliable, this study only measurements with a reliability index of $\geq 60$ were included, in line with OCT device manufacturer specifications. Those measurements were considered reliable. All patients with measurements under 60 were thus not included.

For choroidal evaluation, a $3 \mathrm{~mm}$ horizontal line centered on the fovea was used. The measurements are rendered perpendicular to the choroidal-scleral junction from the outer edge of the hyper-reflective row (retinal pigment epithelial layer). Measured were subfoveal CT (M) and CT at the central fovea time-distance of 500 microns (T500), 1,000 microns (T1000),
1,500 microns (T1500), nasal distances of 500 microns (N500), 1,000 micrometers (N1000) and 1,500 microns (N1500). The CMT was the gap between the inner boundary of the mem lumbar and the foveal core RPE, while subfo lumbar choroid (CT) was the distance from the external border of the mem lumbar till the end of choroid (supra choroidal space) at the foveal center.

SPSS-23 was utilized for all the statistical calculations. Quantitative variables were represented as mean and SD. Qualitative variables like gender and side of eye were frequency and percentage. Independent t-test was applied for the comparison between groups for central macular thickness and choroidal thickness. Stratification with respect to age and gender was done for the retinal \& choroidal thickness using independent t-test. $p$-values of $\leq 0.05$ accepted as being statistically significant.

\section{RESULTS}

One hundred patients fulfilling the inclusion criteria were enrolled. The mean age was $56.27 \pm 14.41$ years. The mean central macular thickness and choroidal thickness were $270.49 \pm 72.38 \mu \mathrm{m}$ and $284.89 \pm$ $96.51 \mu \mathrm{m}$. Of 200 patients, most of them were males (63\%) as compared to females (37\%) (table-I).

Table-I: Descriptive statistics of study variables.

\begin{tabular}{l|c}
\hline Variables & Mean \pm SD \\
\hline Age (years) & $56.27 \pm 14.41$ \\
\hline Central macular thickness $(\mu \mathrm{m})$ & $270.49 \pm 72.38$ \\
\hline Choroidal thickness $(\mu \mathrm{m})$ & $284.89 \pm 96.51$ \\
\hline Variables & Frequency (\%) \\
\hline Gender & $126(63)$ \\
\hline Male & $74(37)$ \\
\hline Female & $98(49)$ \\
\hline Side of Eye & $103(51)$ \\
\hline Left & $100(50)$ \\
\hline Right & $100(50)$ \\
\hline $\begin{array}{l}\text { Droups } \\
\text { macular edema }\end{array}$ &
\end{tabular}

There was statistically significant difference in central macular thickness between both healthy and DR with DME groups $(p<0.05)$, whereas there was no statistical difference between the two groups for choroidal thickness $(p>0.05)$ (table-II).

The retinal \& choroidal thickness were stratified between groups with respect to age \& gender. In age group $\leq 50$ years central macular thickness were statistically significant $(p<0.05) \&$ in age group $>50$ years retinal, choroidal thickness were statistically significant 
$(p<0.05)$. In males retinal thickness were statistically significant $(p<0.05)$ whereas insignificant significance was found in females (table-III).

Table-II: Comparison of mean retinal, choroidal and foveal thickness between both groups.

\begin{tabular}{l|c|c|c}
\hline \multirow{2}{*}{ Variables } & $\begin{array}{c}\text { Healthy } \\
\text { Controls }\end{array}$ & $\begin{array}{c}\text { Diabetic } \\
\text { retinopathy } \\
\text { with diabetic } \\
\text { macular edema }\end{array}$ & $\begin{array}{c}p- \\
\text { value }\end{array}$ \\
\cline { 2 - 3 } & Mean \pm SD & Mean \pm SD & \\
\hline $\begin{array}{l}\text { Central Macular } \\
\text { Thickness }\end{array}$ & $252.66 \pm 29.18$ & $288.14 \pm 94.89$ & 0.001 \\
\hline $\begin{array}{l}\text { Choroidal } \\
\text { Thickness }\end{array}$ & $287.21 \pm 107.79$ & $282.58 \pm 84.22$ & 0.735 \\
\hline
\end{tabular}

due to weakening of the light beam by the intraretinal fluid ${ }^{17}$.

Unsal et al compared Proliferative DR (PDR), Non Proliferative DR (NPDR), DME with healthy control groups using a Optovue RTVue 100-2 (Optovue, Fremont, CA, USA) with the chorioretinal line mode (v 5.1) and reported that CMT was increased statistically significantly in the DME group compared to the control group 9 . In our study as in other studies the DME group showed statistically significant raise in CMT compared to the normal group. Regatieri et al in their study reported insignificant statistical difference in comparison between healthy controls and the NPDR

Table-III: Stratification with respect to age and gender.

\begin{tabular}{|c|c|c|c|c|c|c|}
\hline Age Groups & & Groups & $\mathrm{n}$ & Mean $(\mu \mathrm{m})$ & SD & $p$-value \\
\hline \multirow{4}{*}{$\leq 50$ years } & \multirow{2}{*}{$\begin{array}{c}\text { Central Macular } \\
\text { Thickness }\end{array}$} & Normal & 40 & 249.95 & 27.50 & \multirow{2}{*}{0.02} \\
\hline & & Patient with Diabetic & 12 & 253.67 & 35.70 & \\
\hline & \multirow{2}{*}{$\begin{array}{l}\text { Choroidal } \\
\text { Thickness }\end{array}$} & Normal & 40 & 359.70 & 88.28 & \multirow{2}{*}{0.209} \\
\hline & & Patient with Diabetic & 12 & 333.67 & 51.48 & \\
\hline \multirow{4}{*}{$>50$ years } & \multirow{2}{*}{$\begin{array}{c}\text { Central Macular } \\
\text { Thickness }\end{array}$} & Normal & 60 & 254.51 & 30.37 & \multirow{2}{*}{0.001} \\
\hline & & Patient with Diabetic & 88 & 292.84 & 99.49 & \\
\hline & \multirow{2}{*}{$\begin{array}{l}\text { Choroidal } \\
\text { Thickness }\end{array}$} & Normal & 60 & 238.88 & 91.70 & \multirow{2}{*}{0.05} \\
\hline & & Patient with Diabetic & 88 & 275.61 & 85.61 & \\
\hline Gender & & Groups & $\mathbf{n}$ & Mean $(\mu \mathrm{m})$ & SD & $p$-value \\
\hline \multirow{4}{*}{ Male } & \multirow{2}{*}{$\begin{array}{c}\text { Central Macular } \\
\text { Thickness }\end{array}$} & Normal & 74 & 255.22 & 31.62 & \multirow{2}{*}{0.001} \\
\hline & & Patient with Diabetic & 52 & 303.58 & 94.33 & \\
\hline & \multirow{2}{*}{$\begin{array}{l}\text { Choroidal } \\
\text { Thickness }\end{array}$} & Normal & 74 & 277.16 & 98.32 & \multirow{2}{*}{0.688} \\
\hline & & Patient with Diabetic & 52 & 270.52 & 79.91 & \\
\hline \multirow{4}{*}{ Female } & \multirow{2}{*}{$\begin{array}{c}\text { Central Macular } \\
\text { Thickness }\end{array}$} & Normal & 26 & 245.50 & 19.67 & \multirow{2}{*}{0.169} \\
\hline & & Patient with Diabetic & 48 & 271.42 & 93.61 & \\
\hline & \multirow{2}{*}{$\begin{array}{l}\text { Choroidal } \\
\text { Thickness }\end{array}$} & Normal & 26 & 315.81 & 128.98 & \multirow{2}{*}{0.428} \\
\hline & & Patient with Diabetic & 48 & 295.65 & 87.63 & \\
\hline
\end{tabular}

\section{DISCUSSION}

This study was aimed to compare CT and CMT in diabetic retinopathy patients with diabetic macular edema with normal controls. We found that CT was not significantly different between the two groups while CMT was raised in the DME group compared to the normal group.

A histologically and functionally normal choroid is imperative to retinal function: pathological changes in the choroid due to a variety of disease processes can result in damage to the photoreceptors ${ }^{12,13}$. Histological examination of a diseased specimen may show ischemic changes, microanueurysms, vascular narrowing and dilatation, increased vessel tortuosity and structural changes in the choroidal lobules ${ }^{14.15}$. Until recently it was difficult to image the choroid in vivo but the advent of Heidelberg Spectralis and Cirrus HD-OCT made it possible ${ }^{1,16}$. In patients with DME, it was especially difficult to visualize the choroid/sclera junction group, but the CT was found to be reduced in the DME and PDR groups ${ }^{14}$.

A prospective research by Cho et al, CT and CMT were significantly increased after several session of pan retinal Photocoagulation (PRP). The measurements were taken 1 week before and 1 week following 3 sessions of PRP ${ }^{18}$. The authors proposed that the reason of the increased CMT was the increase in blood flow to the foveal region, from the retinal periphery. Most of the patients we had enrolled in our study were treatment naïve. The rise in CT that Cho et al reported was probably due retinal and choroidal effusion post laser coagulation.

In the study by Unsal et al, CT of the patients with DME showed significant thinning as compared to the controls 9 . This contraindication is probably due to different patient profiles being enrolled in the study. In their study nearly all enrolled patients had advanced diabetic eye disease and had several sessions of the- 
rapy. In contrast the patients in our study were enrolled only on the basis of the presence of DME and were not stratified by DR severity. The pathogenesis of decreased CT is explained by laser photocoagulation in DME leading to decreased choroidal blood flow. Previous studies in NPDR patients with Doppler flowmetry shows a reduction in blood flow to the choroid on indocyanine green angiography ${ }^{19,20}$.

Nagoka et al, showed that NPDR patients with accompanying DME have a reduced choroidal blood flow when compared to NPDR patients without DME. The macular edema is presumed to be secondary to retinal hypoxia due to decreased blood flow ${ }^{20}$. In our study CT in the DME and normal group were not statistically different. However, it has been shown that in macular edema, CT may in fact be falsely low due to signal attenuation and reflection from the choroid as a result of increased ocular opacity. Both Spaide and Wakatsuki et al, have reported that CT tends to decrease with age ${ }^{21,22}$. In our study patients of comparable age were included, so the age factor was eliminated.

There are some limitations in this retrospective study. It has been shown that axial length may be a confounding factor which affects the CT. In our study this was not evaluated. So it is possible that the results might be affected. Several studies report that CT is affected by the point at which the measurement was made, CT was thickest in the subfoveal regions with progressive thinning towards the nasal or temporal area ${ }^{23,24}$. In our study, we only measure the CT subfoveally. A broader range of measurement may improve the accuracy of the CT measurement. For future studies the relationship of glycemic control with CT in patients with diabetic retinopathy can be evaluated using OCT.

OCT Angiography is an improvement upon the already existing OCT devices to assess the choroid noninvasively. In patients with diabetic retinopathy it also gives us an accurate estimation of blood flow changes inside the choroidal vasculature. Further prospective studies are needed to garner a more in depth understanding of the role of choroid and the pathophysiological changes in diabetic retinopathy.

\section{CONCLUSION}

The present study concluded that no significant change in choroidal thickness was observed in patients with diabetic macular edema versus healthy controls, while the retinal thickness was high in patients with diabetic macular edema.

\section{CONFLICT OF INTEREST}

This study has no conflict of interest to be declared by any authors.

\section{REFERENCES}

1. Spaide RF. Enhanced depth imaging spectral-domain optical coherence tomography. Am J Ophthal-mol 2008; 146(4): 496-00.

2. Agrawal RV, Biswas J, Gunasekaran D. Indocyanine green angiography in posterior uveitis. Indian J Ophthalmol 2013; 61(4): 148-59.

3. Matsunaga D, Yi J, Puliafito CA, Kashani AH. OCT angiography in healthy human subjects. Ophthalmic surgery, lasers \& imaging retina 2014; 45(6): 510-15.

4. Musat O, Colta D, Cernat C, Boariu AM, Alexandru L, Georgescu $\mathrm{R}$, et al. New perspectives in retinal imaging - angio OCT. Romanian J Ophthalmol 2016; 60(2): 63-67.

5. Spaide RF, Fujimoto JG, Waheed NK, Sadda SR, Staurenghi G. Optical coherence tomography angiography. Prog Retin Eye Res 2018; 64(1): 1-55.

6. Danilova I, Medvedeva S, Shmakova S, Chereshneva M, Sarapultsev A, Sarapultsev P. Pathological changes in the cellular structures of retina and choroidea in the early stages of alloxaninduced diabetes. World J Diabetes 2018; 9(12): 239-51.

7. Khadamy J, Abri Aghdam K, Falavarjani KG. An Update on Optical Coherence Tomography Angiography in Diabetic Retinop J Ophthal Vision Res 2018; 13(4): 487-97.

8. Boonarpha N, Zheng Y, Stangos AN, Lu H, Raj A, Czanner G, et al. Standardization of choroidal thickness measurements using enhanced depth imaging optical coherence tomography. Inter J Ophthalmol 2015; 8(3): 484-86.

9. Ünsal E, Eltutar K, Zirtiloğlu S, Dinçer N, Erkul SÖ, Güngel H. Choroidal thickness in patients with diabetic retinopathy. Clin Ophthalmol (Auckland, NZ) 2014; 8(1): 637-42.

10. Lee R, Wong TY, Sabanayagam C. Epidemiology of diabetic retinopathy, diabetic macular edema and related vision loss. Eye and vision (London, England) 2015; 2(1): 17-20.

11. Grading diabetic retinopathy from stereoscopic color fundus photographs - an extension of the modified airlie house classification. ETDRS report 10. Early treatment diabetic retinopathy study research group. Ophthalmol 1991; 98(Suppl-5): 786-06.

12. Fukushima I, McLeod DS, Lutty GA. Intrachoroidal microvascular abnormality: a previously unrecognized form of choroidal neovascularization. Am J Ophthalmol 1997; 124(4): 473-87.

13. Wang W, Lo ACY. Diabetic Retinopathy: Pathophysiology and Treatments. Int J Mol Sci 2018; 19(6); 1816-20.

14. Fryczkowski AW, Sato SE, Hodes BL. Changes in the diabetic choroidal vasculature: scanning electron microscopy findings. Ann Ophthalmol 1988; 20(8): 299-5.

15. Hidayat AA, Fine BS. Diabetic choroidopathy. Light and electron microscopic observations of seven cases. Ophthalmol 1985; 92(4): 512-22.

16. Regatieri CV, Branchini L, Carmody J, Fujimoto JG, Duker JS. Choroidal thickness in patients with diabetic retinopathy analyzed by spectral-domain optical coherence tomography. Retina 2012; 32(3): 563-68.

17. Imamura Y, Fujiwara T, Margolis R, Spaide RF. Enhanced depth imaging optical coherence tomography of the choroid in central serous chorioretinopathy. Retina 2009; 29(10): 1469-73.

18. Cho GE, Cho HY, Kim YT. Change in subfoveal choroidal thickness after argon laser panretinal photocoagulation. Inter J Ophthalmol 2013; 6(4): 505-9. 
19. Schocket LS, Brucker AJ, Niknam RM, Grunwald JE, DuPont J, Brucker AJ. Foveolar choroidal hemodynamics in proliferative diabetic retinopathy. Int Ophthalmol 2004; 25(2): 89-94.

20. Nagaoka T, Kitaya N, Sugawara R, Yokota H, Mori F, Hikichi T. Alteration of choroidal circulation in the foveal region in patients with type 2 diabetes. Br J Ophthalmol 2004; 88(8): 1060-3.

21. Spaide RF. Age-related choroidal atrophy. Am J Ophthalmol 2009; 147(5): 801-10.

22. Wakatsuki Y, Shinojima A, Kawamura A, Yuzawa M. Correla- tion of aging and segmental choroidal thickness measurement using swept source optical coherence tomography in healthy eyes. PLos One 2015; 10(12): e0144156-60.

23. Manjunath V, Taha M, Fujimoto JG, Duker JS. Choroidal thickness in normal eyes measured using Cirrus HD optical coherence tomography. Am J Ophthalmol 2010; 150(3): 325-29.

24. Sheth JU, Giridhar A, Rajesh B, Gopalakrishnan M. Characterization of macular choroidal thickness in ischemic and nonischemic diabetic maculopathy. Retina 2017; 37(3): 522-28. 